\title{
LA TRANSICIÓN EN DISPUTA: CON UÑAS Y DIENTES (PAULINO VIOTA, 1978) ${ }^{1}$
}

\author{
TRANSITION TROUBLE: \\ CON UÑAS Y DIENTES (PAULINO VIOTA, 1978)
}

Rubén GARCÍA LÓPEZ

Universidad de Valparaíso

p9prod@gmail.com

\begin{abstract}
Resumen: Este trabajo analiza la dimensión ideológica del largometraje Con uñas y dientes, una reflexión sobre la Transición española (1975-1982) desde una perspectiva marxista. Para ello, se considerará el abandono por parte del autor de sus anteriores posiciones estéticas y la asunción de códigos genéricos convencionales, analizando su construcción narrativa y considerando el contexto cinematográfico y político del momento, así como la relación del filme con la labor del Nuevo Frente Crítico, principalmente con la visión del colectivo Marta Hernández sobre los últimos años del franquismo y de la revista Contracampo sobre la Transición.
\end{abstract}

Palabras clave: Paulino Viota. Con uñas y dientes. Cine de la Transición. Contracampo. Nuevo Frente Crítico. Marta Hernández.

Abstract: This paper studies the ideological dimension of the film Con uñas y dientes, a critical view on the Spanish Transition (1975-1982) from a marxist perspective. For that purpose, the author's abandonment of his previous aesthetic positions in favor of more conventional generic codes will be considered, analyzing the film's narrative construction. For this purpose, the cinematographic and political context of the period will be taken on account, as well as the film's connection with the work of the Nuevo Frente Crítico (New Critical Front), mainly the colective Marta

${ }^{1}$ El presente trabajo forma parte del Proyecto Fondecyt Postdoctorado n. ${ }^{\circ} 3180086$. 
Hernández's view on the last years of francoism and that of the review Contracampo on Transition.

Key Words: Paulino Viota. Con uñas y dientes. Transition Cinema. Contracampo. New Critical Front. Marta Hernández.

\section{TÁCTICAS}

En 1977, año en que realiza Con uñas y dientes, Paulino Viota es un joven cineasta autor de varios cortometrajes desconocidos y un lejano largometraje independiente, Contactos (1970), que vinculado en cierta medida a la estética materialista entonces en germen en ciertos ambientes cinematográficos franceses, retrataba la difícil cotidianidad de una pareja de camareros y un grupo político clandestino en el Madrid franquista de 1970 (Pena, 1997: 677-679). Evaluando tras una larga y problemática distribución sus resultados, Viota y su colaborador Javier Vega habían decidido emprender un nuevo proyecto explícitamente político inspirado en las piezas didácticas de Bertolt Brecht. Tras emplear varios años en el trabajo, y realizar diversos borradores con enfoques diversos, nunca lograrán llevarlo a cabo ${ }^{2}$. Tanto por los productores consultados, como por ellos mismos, el guion es primero considerado demasiado vanguardista, después demasiado didáctico. En el proceso se reducen los campos laborales representados, el montaje basado en yuxtaposiciones secuenciales se torna lineal ${ }^{3}$, los elementos más explícitamente discursivos se integran en una narración más convencional. Cada nuevo enfoque obtiene el mismo resultado: la imposibilidad de realizarse, por unas razones u otras. El proceso completo dura 4 años.

Repentinamente, Viota decide un inesperado cambio de rumbo, y a lo largo de 1977 escribe y realiza un nuevo largometraje que explicará a su padre, un industrial santanderino participante en la producción, en una carta escrita el 13 de marzo, dando fe en ella de un nivel de pragmatismo

\footnotetext{
${ }^{2}$ Los títulos son también variados: “...Y el oro de sus cuerpos", "Tácticas”, "Los explotados hablan de explotación", "No es sordo el mar".

${ }^{3}$ Tal montaje, bien visible en Contactos, fue muy defendido por los Cahiers du Cinéma de la época, véanse por ejemplo algunas de las reflexiones de Jacques Rivette en Narboni, Pierre y Rivette (1969: 20).
} 
hasta el momento inexistente:

Hemos seguido una idea que ya te mencioné hace meses: un caso de corrupción industrial, del tipo de los de Matesa o Reace, pero desde luego inventándolo todo y sin ninguna semejanza con ningún caso real para evitar cualquier problema. Antes de hacerlo, pulsamos la opinión de varias personas y el propio Emiliano Piedra nos dijo que es un tema que le interesaría en una película para producir él. O sea que hemos ido sobre seguro y hemos trabajado un poco a tiro hecho. Estos temas, ahora que se está tirando de la manta, dadas las nuevas condiciones politicas, interesan sobremanera y si te fijas en las revistas, por ejemplo, no hay número en que no aparezcan relatos sobre ellos, o informes. Es un tema de actualidad. Hemos añadido una historia de amor con erotismo por parte de uno de los trabajadores de la fábrica donde ocurre la estafa para cumplir también con ese requisito imprescindible del erotismo en el cine español de hoy. Hemos hecho algo asi como un traje a medida, veremos si sirve para algo (García López, 2017: 310).

Para empezar, la nueva táctica implicará una gran ruptura con el modelo adoptado en Contactos, que puede entenderse pensando en la célebre clasificación de relaciones entre cine e ideología propuesta por el artículo "Cinéma / idéologie / critique", publicado menos de una década atrás en Cahiers du Cinéma. Si Contactos era clara perteneciente a la categoría $\mathrm{B}$, películas que operan políticamente al nivel de los significados pero al mismo tiempo proceden "a una deconstrucción crítica del sistema de representación" (Comolli, Narboni, 2008: 79)4, su sucesora se ubicará en la categoría $\mathrm{D}$, condenada por la revista francesa: filmes de contenido político explícito "pero que de hecho no operan una verdadera crítica del sistema ideológico en el que están inmersos, pues adoptan, sin cuestionarlos, el lenguaje y los modos de figuración" (Comolli y Narboni, 2008: 79). Aunque el giro de Viota es más rotundo de lo previsto, este y Vega ya habían manifestado explícitamente en notas del proyecto anterior la voluntad de asumir lo que llamarán "lenguaje del cine de Hollywood" (García López, 2017: 303) y utilizar sus modelos narrativos y referencias genéricas en el desarrollo de una historia que no por ello renunciaría a un discurso contrario a la ideología que supuestamente iría

\footnotetext{
${ }^{4}$ Si bien cito según una traducción española muy posterior, el artículo original se publica en 1969 , en el número 216 de la publicación francesa.
} 
implicada en aquellos. Borrador a borrador hasta la película finalmente realizada, tanto vanguardia - primacía de la forma: Contactos - como didactismo - primacía del discurso político: proyecto intermedio- se ven progresivamente abandonados a favor de una decidida voluntad de intervención ideológica: lo primero facilita la comprensión del discurso, lo segundo la aceptación del mismo por parte de la industria, lo que sumado a la orientación genérica adecuada procura una comercialidad que allana las dificultades para llegar a su público.

Las implicaciones del cambio no pasaban desapercibidas a Viota, que en la entrevista realizada por Contracampo con motivo del estreno de Con uñas y dientes en Madrid ${ }^{5}$, afirmará:

\begin{abstract}
Yo creo que es posible un cine que utilice un lenguaje transparente o, por ser pedante, que no ponga el lenguaje en el primer término de la contradicción, y que no sea al mismo tiempo telefilm. [...] Hay toda una crítica de izquierdas que ataca rigurosamente toda ficción de izquierdas. Pero eso, llevado al límite, no nos lleva a otra cosa que no sea negar todo cine que no tenga por objeto de reflexión el propio lenguaje. En definitiva, a esclerotizarse (Fernández Torres y G. Requena, 1979: 22).
\end{abstract}

En la entrevista Viota defiende Contactos, pero manifiesta sus dudas sobre su efectividad, en tanto la importancia de la articulación común forma-ideología propia de la categoría $\mathrm{B}$, en realidad, imposibilitaría a su entender que el trabajo ideológico logre dirigirse a lugar distinto que la forma misma. Por ello, Con uñas y dientes toma como objeto explícito y protagónico las relaciones de producción y la lucha obrera; el proyecto anterior también lo hacía, pero incluso cuando la influencia vanguardista fue eliminada aún la narración era en los últimos borradores patentemente secundaria al discurso. En Con uñas y dientes nada perturbará el desarrollo del argumento, sin que forma, género y narración dejen de ser por ello medio para articular una línea ideológica, hacerla comprensible y persuasiva. Dado que la forma pasa a ser entendida como modo de transmisión, no determinante ideológicamente en tanto tal, el lenguaje del cine de Hollywood puede ser útil para una ideología opuesta a la dominante

\footnotetext{
${ }^{5}$ Rodada entre agosto y octubre de 1977, la película se estrenó en Sevilla, el 7 de marzo de 1978, pero decisiones de Viota a última hora le llevaron a doblar al protagonista y hacer cambios fundamentales en el montaje. Esta nueva versión se estrenará el 13 de septiembre en el Festival de San Sebastián y, con una deficiente distribución, no llegará a Madrid hasta el 28 de mayo de 1979.
} 
siempre y cuando sus elementos sean dispuestos de acuerdo con una línea política correcta; si esto se logra hacer con éxito, no habrá conflicto entre la narrativa clásica y el discurso marxista, y será posible hacer una película anticapitalista con las formas del cine de Hollywood. Por supuesto, esto supone negar la mayor de la crítica materialista - implicada en la definición de la categoría D - afirmando que un código o formas determinadas no implican una ideología determinada, o que cuando menos tal implicación no es necesaria y puede en consecuencia ser intervenida.

Los modos de la intervención de Viota sobre su modelo van a ser los siguientes: establecer a un miembro de la clase obrera como protagonista, en alianza con otro de la clase intelectual, ambos igualmente activos en la lucha social; establecer a un miembro de la patronal como villano; introducir elementos equivocados en el comportamiento del primero para connotar los peligros del liderazgo único en los movimientos sociales, y asimismo utilizar al personaje femenino y las escenas de sexo para, respectivamente, cuestionar el lugar tradicionalmente secundario otorgado a las mujeres en la lucha política y proponer un tipo de sexualidad no tradicional; utilizar una huelga como escenario central de una trama criminal, utilizando tipos y situaciones propias del cine de acción - matones, palizas, secuestros, e incluso asesinos a sueldo - para representar la violencia ejercida por la patronal, así como para generar una lectura sobre el devenir del proceso de reforma posterior al fin de la dictadura.

En lo que sigue, trataré de exponer la articulación de cada punto y analizar sus problemas específicos en relación con las intenciones manifiestas.

\section{LUCHA DE CLASES}

Con uñas y dientes afronta pues una representación de la lucha de clases en el muy problemático contexto de la España de 1977, concretándola en una huelga industrial y, en último término, un pulso entre dos hombres: el director de una fábrica (don Rodolfo) y un líder sindicalista (Marcos) en el secreto de que aquel, para llevar a cabo una estafa, ha mentido sobre el volumen de stock de su empresa. Como el sostenimiento de la huelga podría desvelar la estafa, Rodolfo intentará ponerle fin dando una paliza a Marcos, forzándole a esconderse para así facilitar la rendición de sus compañeros. Marcos se oculta en casa de una camarada profesora (Aurora), 
pero el desarrollo del enfrentamiento acabará con el asesinato del obrero en su interior, a manos de un asesino a sueldo.

Un primer aspecto que singulariza a Con uñas y dientes en su contexto cinematográfico radica en que sus protagonistas son predominantemente obreros y militantes políticos, que atiende a un acontecimiento tan específico de la lucha obrera como es una huelga, y que lo hace además en un contexto de riguroso presente, "el espacio de tiempo existente entre la Ley de Reforma Política de diciembre de 1976 y las elecciones generales de junio de 1977" (Fernández Torres y G. Requena, 1979: 20). Un elemento muy valorado por la crítica afín será no en vano su aportación de ese nuevo verosímil fílmico. En el extenso análisis que del filme ofrecerá Contracampo, Julio Pérez Perucha evaluará entre otras cosas la presencia y función de la clase obrera en distintos tipos de cine implicados en la obra. Así, Perucha juzga que en el cine de autor por un lado las luchas populares se reducen "a decorado más o menos cercano" (Pérez Perucha, 1979a: 14), y por otro su audiencia no es la clase obrera, destinataria al contrario de "los grandes espectáculos subsidiarios del cine de género clásico" (Pérez Perucha, 1979a: 14). Sin embargo, en este los obreros solo aparecerían "en tanto que elementos mecánicos de un espectáculo o en tanto que expresiones del lugar que les reserva la ideología dominante" (Pérez Perucha, 1979a: 14), al igual que en el cine político más popular en la época, el norteamericano o el de autores como Costa Gavras o Elio Petri, la asunción del modelo hollywoodiense habría implicado también la de sus protagonistas — burócratas, policías, abogados, periodistas...- nunca pertenecientes a la clase obrera. Todo esto tendría el efecto indeseado - y a la vista tanto de Viota como de Contracampo, indeseable - de invisibilizar y eliminar la importancia de la lucha obrera, que en el caso español venía siendo capital como mínimo desde la gran huelga asturiana de 1962:

En 1964, las remuneraciones totales de los asalariados incluidas las cotizaciones a la seguridad social no sumaban la mitad de la riqueza producida en un año, el 47,5\% de la Renta Nacional. El Excedente Bruto de Explotación (EBE), esto es, la parte destinada a compras de materias y reinversiones, además de beneficios e impuestos, era entonces del 52,5\%. En 1970, las cifras se habian invertido, los salarios eran ya el 52\% frente al 48\% del EBE. En 1976, la presión obrera había arrancado otros cinco puntos más sobre el total de la Renta Nacional, sumaba el 57\%. Los 
aumentos salariales se habian despegado definitivamente de los limites impuestos por los convenios. De 1970 a 1976 los salarios reales medios acumularon un crecimiento de casi el 40\%, la productividad sólo creció un 23,7\%. Por primera vez desde los años treinta, las luchas de fábrica estaban recortando las rentas del capital, presionando por encima de las posibilidades de reparto de los excedentes de capital.

Las estadísticas laborales confirman el paso fuerte del movimiento obrero. En 1966 - año por lo demás bastante conflictivo - se contabilizaron 205 huelgas, participaron 100.000 trabajadores y se perdieron casi dos millones de horas. En 1970 el número de huelgas se cuadruplicó hasta sumar 817, implicaron a más de 300.000 huelguistas y se llevaron por delante cerca de siete millones de horas. En 1976 se contabilizaron 1.568 conflictos, en los que participaron 3,5 millones de trabajadores y en los que se perdieron 110 millones de horas (Rodríguez López, 2015: 34).

Con la elección de su tema y protagonistas, Viota llama la atención sobre un elemento determinante de su presente: la lucha obrera y su importancia mayor en el devenir del país, nunca reconocida por su cine. Que Contracampo reaccionara positivamente a esto, no es raro en tanto la evolución del cineasta no deja de responder a importantes planteamientos que el Nuevo Frente Crítico (NFC) realizará a lo largo de la década, partiendo desde el seminal Cine español: algunos materiales por derribo ${ }^{6}$, de los hermanos Pérez Merinero, y concentrándose destacadamente en las capitales aportaciones del Colectivo Marta Hernández ${ }^{7}$, cuyas críticas al aparato cinematográfico español siempre estuvieron predominantemente basadas en el estudio de sus relaciones de producción o en su plano más directamente ideológico, señalando por ejemplo que el problema de Carlos Saura, autor predilecto de la progresía intelectual del momento, era que en sus películas se limitaba a balbucear "plañideramente algunas contradicciones culturalistas de carácter secundario dentro del sistema, sin explotarlas" (Hernández, 1976: 258). Salvo en sus críticas cinematográficas, donde se defendía claramente una "estética materialista" (Hernández y Maqua, 2016: 50), marcada por su oposición a la confusión entre signo y realidad propia del idealismo estético, en su producción central, recopilada en los dos libros publicados en vida del colectivo, la forma nunca será el eje del

\footnotetext{
${ }^{6}$ Publicado en 1973, recientemente puede leerse la versión íntegra del texto, sin los numerosos cortes efectuados por la editorial, y junto a otras publicaciones de los hermanos Pérez Merinero y los dos libros de Marta Hernández, en López Sangüesa (2019: 95-207).

${ }^{7}$ Sobre el NFC y Marta Hernández, véase López Sangüesa (2019: 5-93).
} 
análisis, que antes bien prestará "una especial atención a las contradicciones que sacuden el aparato cinematográfico español, al análisis de la industria, a las posibilidades de una práctica significante de oposición dentro del cinema, etc.” (Hernández, 1976: 186). Más aún, incluso en las críticas, para el análisis netamente ideológico que Maqua propone resultará clave la distinta tipología social de los personajes del filme:

En cada uno de ellos -y en especial en su máximo portavoz: el protagonista - es preciso conocer origen de clase, situación de clase actual —en el relato-, y conciencia real de esta situación, para poder articular las estructuras formales del relato con las estructuras ideológicas que sustenta (Hernández y Maqua, 2016: 64).

Para Viota, este es exactamente el núcleo del que partir para tomar las formas del cine comercial habitual y utilizarlas en la línea ideológica deseada. La elección del protagonismo obrero será ya de por sí un modo de violentar los contenidos habituales del cine dominante que, progresista o no, erradica a la clase obrera de sus imágenes y narraciones, y lanzar una serie de consignas que se dirijan a aquella, y no a los conflictos internos de la clase burguesa que el NFC entendía eran objeto privilegiado de la producción cinematográfica progresista hispana. Por ello, no solo son obreros los protagonistas, sino militantes en el curso de una huelga. No se tratará de buscar la identificación con obreros sin más, sino con obreros en un proceso de lucha, con la patronal como enemiga.

\section{EL IMPUESTO HEROICO}

De esto se seguirá un problema, que es la adopción de un modelo narrativo clásico, vinculando todas las peripecias a un conflicto central y, sobre todo, a un protagonista individual. Según David Bordwell:

La película clásica de Hollywood presenta individuos psicológicamente definidos que luchan por resolver un problema claramente indicado o para conseguir unos objetivos específicos. En el transcurso de esta lucha, el personaje entra en conflicto con otros o con circunstancias externas. La historia termina con una victoria decisiva o una derrota, la resolución del problema o la consecución o no consecución clara de los objetivos: el medio causal principal es, en consecuencia, el personaje, un individuo diferenciado, dotado con una serie coherente de rasgos, cualidades y 
conductas evidentes (Bordwell, 1996: 157).

Para entender el modo en que Viota se relaciona con este esquema, podemos recordar que Hernández / Maqua lo resumían en la presencia de tres tipos de personajes, beneficiarios, enemigos y aliados: "Un sujeto beneficiario tiene el proyecto de conseguir un objetivo con la ayuda de sus aliados para vencer todos los obstáculos y enemigos que se le opongan" (Hernández y Maqua, 2016: 63) ${ }^{8}$. Tan concisa descripción favorece la identificación — también presente en Bremond y Bordwell- entre narración y lucha, lo que ya da buena fe de lo que se considera está en juego en el trato con el modelo. Para articular tal lucha, Viota hará que el origen y situación de clase del protagonista, así como la conciencia del mismo, estén en el lugar apropiado para que la identificación entre personajes y espectadores - criticable desde los postulados de la crítica materialista al provocar que las clases populares introyecten valores contrarios a sus intereses a través de su adhesión a un protagonista ajeno a ellas - devenga admisible no solo al pertenecer este a su misma clase social sino ser además un agente activo en la defensa de sus derechos, pudiendo así a través de su lucha transmitirles valores que en este caso sí les serían favorables.

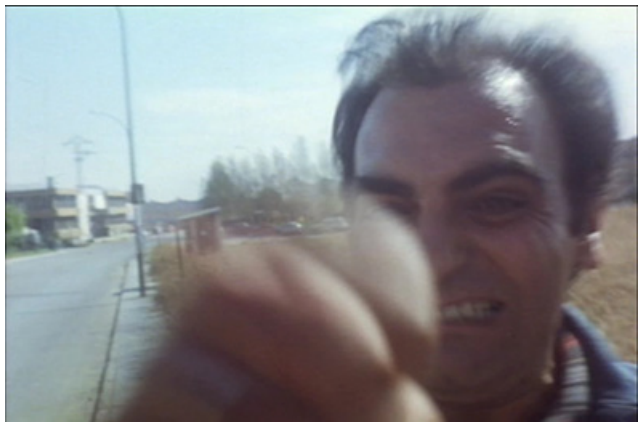

Figura 1

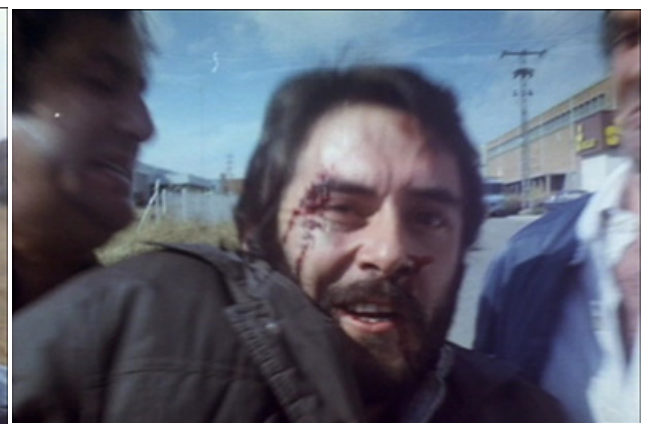

Figura 2

${ }^{8}$ Tal descripción tiene una declarada deuda con los artículos del volumen colectivo - publicado originalmente en Francia en 1966 como número 8 de la revista Communications - Análisis estructural del relato, véase principalmente Bremond (1972: 87-109). 


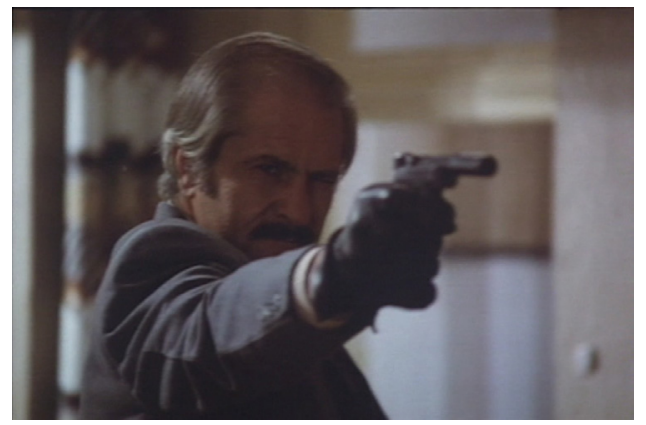

Figura 3

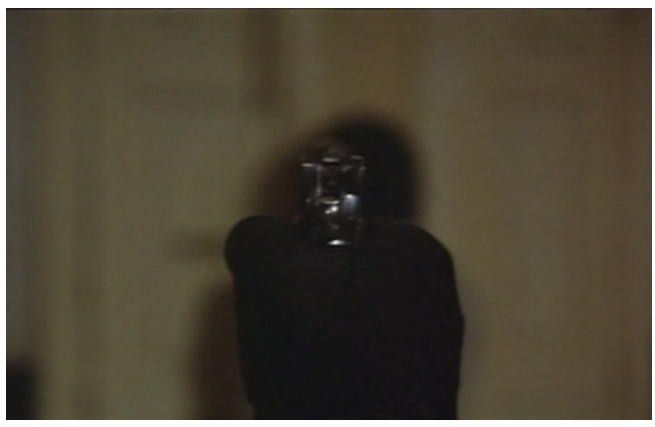

Figura 4

Desde el plano de apertura de Con uñas y dientes, el punto de vista del público será identificado con el de Marcos, el obrero protagonista, al que se presenta recibiendo una paliza a manos de tres matones de la patronal. La película se abre con un plano subjetivo de este, mostrando el puño del matón dirigiéndose a la cámara, seguido de otro de su rostro recibiendo el golpe [Figs. 1-2], que permiten situar inequívocamente el lugar del espectador en la narración, férreamente mantenido en los minutos siguientes. Las tomas subjetivas serán recurrentes a lo largo del filme, en momentos en ocasiones tan claves como cuando, a la llegada de Marcos a la casa de Aurora, una larga toma subjetiva de su mirada sirve para darnos a conocer el espacio donde transcurrirá buena parte de la historia. El manejo del punto de vista será uno por los cuales el trabajo formal favorece la intencionalidad ideológica de la narración. Los planos subjetivos solo corresponden a Marcos y Alicia, los dos protagonistas militantes, y sintomáticamente será en un plano subjetivo que Marcos perderá la vida, esta vez uno que representa tanto la mirada de su asesino como la de la mira de la pistola con que lo dispara [Figs. 3-4].

Las dificultades llegarán no obstante por la razón de que, tomando un héroe como eje de su película, lo que Viota busca no es sino apropiarse discursivamente del obligatorio protagonismo individual y estructura heroica del modelo narrativo y género elegidos, usándolo para denunciar los peligros del personalismo para la lucha obrera, que debiera dirigirse por la toma colectiva de decisiones. El héroe es convocado, dicho de otro modo, con la intención de cuestionar su existencia.

Hernández / Maqua señalan la ausencia o escasez de aliados como 
un rasgo importante para definir la existencia de un protagonismo absoluto (Hernández y Maqua, 2016: 62-63). En efecto, Marcos apenas tiene aliados, pero es necesario entender por qué. En realidad, tiene muchos, no solo Aurora o Lucía - su esposa-, sino sus compañeros sindicalistas y todos los obreros en huelga. Sin embargo, se niega su ayuda al no informarles de la estafa del director. Con ello el propio personaje genera su protagonismo absoluto, y ello por un error y exceso de celo que habrá de costarle la vida, amén de dejar a todos los huelguistas indefensos ante sus malas decisiones. Viota dirá que "la idea del filme era criticarle en su actividad como líder — es decir, se equivoca-, y después salvarle como persona" (Antolín, 1979: 49). Además de ideológicamente acertado Marcos es voluntarioso, valiente y decidido, pero al tiempo sus decisiones se rebelan gravemente equivocadas, pues la negativa a desvelar a sus compañeros la estafa deja a los huelguistas inadvertidamente atados de pies y manos y atrapados entre un engaño y un error, sumidos en una total ceguera ante las condiciones reales de su lucha. Un exceso de celo, una confianza excesiva en su liderazgo, hacen a Marcos considerarse el único capaz de guardar el secreto y saber qué hacer con él.

El problema, principalmente para el público popular y obrero al que el filme está dirigido, será el conflicto entre el establecimiento de un héroe que comporta una identificación férrea no solo mecánica sino ideológica, y las decisiones sistemáticamente equivocadas y, llegado cierto punto, manifiestamente caprichosas e irresponsables, del mismo9. Por ejemplo, Marcos piensa que Rodolfo tendrá que transigir con los huelguistas si no quiere que su timo se descubra, pero esto no muestra sino un grave desconocimiento de la estructura del poder en la fábrica, impropio de un líder tan importante: el director debe conseguir la aquiescencia del consejo de dirección, que es quien tiene el poder en última instancia, y por supuesto no va a lograrlo porque aquel está convencido de tener los almacenes llenos y, por tanto, de que ganará la huelga. Todo espectador, y sobre todo obrero, puede percibir claramente el error de no descubrir la estafa a los compañeros, y con ello el evidente absurdo de la estrategia de Marcos.

Como bien detecta Pérez Perucha, al ser a pesar de todo salvado

\footnotetext{
${ }^{9}$ Entre las más graves, y trascendentes para el desarrollo del filme, la amenaza telefónica a la esposa de Rodolfo y la decisión de ir a la asamblea pese a estar escondido, y hacerlo además solo. Sobre otros comportamientos inconsecuentes, acciones irreflexivas y errores, véase García López (2017: 319-321).
} 
por la película, sucederá que los comportamientos de Marcos no serán entendidos "por los públicos populares a quien interpela el film como representación autocrítica de un obrero no tan 'bueno', sino como errores en la caracterización del personaje" (Pérez Perucha, 1979b: 15). Para esto es fundamental el profundo rechazo moral que el personaje no podía dejar de causar en un público obrero por la infidelidad a su esposa y camarada. Llegado cierto punto, Marcos y Aurora se convierten en amantes, relación extraconyugal que fue según Viota lo más discutido en las proyecciones para obreros que tuvo la película (Fernández Torres y G. Requena, 1979: 25). El filme choca aquí no solo con ese posible puritanismo de la clase trabajadora que tanto gusta de denunciar la intelectual, sino con el hecho de que, en un contexto militante, una traición así no lo es solo a la pareja, sino a una compañera de lucha; es una traición no solo afectiva sino política, a una camarada. Según Viota el hecho supone la reivindicación de una "sexualidad desculpabilizada" (Fernández Torres y G. Requena, 1979: 25), pero en la década de los 70 era muy difícil que un obrero militante de la edad de Marcos fuera a identificarse y menos aún aceptar, tal proceder ${ }^{10}$.

En definitiva, los hábitos adquiridos por la larga vigencia del modelo narrativo elegido por Viota harán entender al héroe como modélico siguiendo la norma por la cual "a situaciones y personajes negativos y criticados corresponden, en correlato amplificador, situaciones y personajes positivos y glorificados. O sea, a patronos malos, obreros buenos" (Pérez Perucha, 1979b: 15). La polaridad narrativa e ideológica establecida por Viota conlleva una identificación a ambos niveles con el héroe, que exige mucho cuidado para connotar negativamente los fallos políticos. La vía más sencilla y habitual, hacer que el personaje sea impecable en todo salvo en eso, para hacer evidente la diferencia, se ve no obstante perjudicada por un comportamiento que se muestra equivocado en numerosas ocasiones, y casi dinamitada por la infidelidad a la compañera. La intención de que se advierta que el dirigente se equivoca en el plano político salvándolo en los restantes, se ve pues irresuelta tanto por el hábito que establece al héroe como íntegramente modélico como por su comportamiento personal, de modo que, en ausencia de alguna vía que califique los errores

\footnotetext{
${ }^{10}$ Otro motivo de rechazo, este ya hacia el conjunto de la película y presente en su recepción crítica (Latorre, 1979: 64-65), puede ser por supuesto el advertir la erótica como una intrusión de mera intencionalidad comercial que ensuciaría la integridad ideológica del producto.
} 
como tales, estos no se entenderán sino como inconsecuencia y error en la caracterización o, peor aún, defensa de un individuo en el fondo no tan modélico como se dice.

\section{CUESTIÓN DE GÉNERO}

Pérez Perucha sugiere que el terrorismo ofrecía ficciones que se adaptaban óptimamente al gusto hollywoodiense al tiempo que eran bien asumidas por el cine político. Por un lado, el cine de género facilita la aquiescencia de la clase trabajadora, su auditorio natural; por otro, el thriller posee una pertinencia casi realista, al permitir mostrar los extremos violentos con que podía encontrarse, y se encontraba, la lucha obrera. El propio Viota, años más tarde, recordará la intensidad de aquel periodo:

El 18 de noviembre las Cortes se habian hecho el harakiri aprobando la reforma política; a continuación, los acontecimientos se precipitan: el 5 de diciembre, el PSOE celebra su congreso, pese a que los partidos aún no están legalizados; el 11, los GRAPOS secuestran a Oriol, presidente del Consejo de Estado, para influir en el referéndum de la Reforma Política, que se celebra el día 15; el 20, los ultras insultan a Fernández Miranda, presidente del Consejo del Reino, en un homenaje a Carrero; el 22, Carrillo es detenido y el día 30 lo sueltan; el 5 de enero se disuelve el Tribunal de Orden Público; el 11 se abren negociaciones oficiales entre el gobierno y la oposición democrática; el 23, en una manifestación por la amnistía, los ultras matan a un estudiante; el 24 es el más negro, la policía mata a una muchacha en una manifestación por la muerte anterior, los GRAPO secuestran a Villaescusa, presidente de la Justicia Militar, y ultras ligados al Sindicato Vertical, matan a cinco personas y hieren a otras cuatro en un despacho laboralista del PCE en Atocha; el 28 los GRAPO matan a dos policías y un guardia civil, y al día siguiente, en el funeral, algunos militares increpan al vicepresidente Gutiérrez Mellado. El 12 de febrero la policía libera a Oriol y Villaescusa (Viota, 1997: 272).

...Y el 28 de febrero se registra el primer guion de Con uñas $y$ dientes, que no se negará al aporte espectacular de la violencia, pero hace que el terrorismo provenga de la patronal. Como puede verse, en el momento en que se realiza, la violencia está al orden del día y por ello una ficción propia de un thriller deviene válida para representar este específico momento social. Ello se observa, destacadamente, en la escena 
del asesinato de Marcos, perpetrado por un asesino a sueldo que delata con toda evidencia su carácter de tipo narrativo, de figura genérica, pero con ello su voluntad metafórica de denunciar la falta de límites en la violencia que la patronal ejerce sobre aquellos que se levantan contra ella.

Ha de añadirse no obstante un matiz importante, que supone un nuevo problema derivado de asumir la individualización de los conflictos propia del modelo: el terrorismo en la película no es tanto el de la patronal cuanto el de uno de sus miembros, que ejerce la violencia no en tanto director de la fábrica sino en tanto estafador a punto de ser descubierto. Bien es cierto que el timo de don Rodolfo es presentado como una práctica que no entra en contradicción alguna con la dinámica capitalista, lo que supone denunciar la corrupción inherente a la misma y, así y todo, su impunidad, pero lo cierto es que el detonante de todo es una actividad criminal y no la tensión específica creada por el pulso entre una fábrica y sus obreros a través de una huelga. La presión a la cual responde el director no es la que surge de la imposibilidad de cumplir con las ventas por la falta de producción, sino la de que la huelga descubra su timo. Así, el conflicto específico de la película parte de la labor criminal de don Rodolfo, no de la lucha obrera.

Esto complica en gran medida la efectividad ideológica del marco genérico, pues en el fondo la clase obrera acaba jugando un papel subsidiario, implicada en una lucha entre dos antagonistas en la que se ve imposibilitada para poder operar activamente, sujeto mera y puramente paciente. La violencia no proviene de una patronal que intenta parar una huelga violentamente por el modo en que amenaza sus intereses de clase, sino de un miembro de tal clase y tal patronal que intenta detener la huelga para impedir que ponga al descubierto su trama criminal ${ }^{11}$. Si bien Rodolfo puede hacer lo que hace por su posición económica, ni él deja de ser en primer término un criminal ni Marcos el hombre que podría descubrirlo y derribarlo. Si sus condiciones socioeconómicas determinan su posición, serán las estrictamente personales las que privilegiadamente activen y configuren todo el desarrollo argumental. No estamos por tanto ante la historia de una huelga contada en formato thriller, sino ante un conflicto

\footnotetext{
${ }^{11}$ El propio Viota reconocería tácitamente este hecho al afirmar, comentando los problemas del filme para la distribución, que "ha habido exhibidores que han rechazado la película, porque hay en ella ataques a los capitalistas. Lo que hay son ataques a un capitalismo criminal" (Bayón, 1979).
} 
de tipo criminal inserto en el contexto de uno político. El hecho tendrá otra consecuencia indeseada: provocar que la atención enorme que Viota presta a la huelga, y destacadamente las explicaciones didácticas relativas a la misma, sean experimentadas como una interrupción de la auténtica historia central de la película.

Idéntico problema surgirá con la relación entre Marcos y Aurora, si bien en menor medida y por diferentes razones, que aquí se limitan a la mera interrupción tanto de la trama criminal como de la política por una vía extraña, una infidelidad incómoda donde tampoco es fácil leer en la interpretación de los actores los sentimientos en juego. Dicho de otro modo, y enlazando así con afirmaciones anteriores, la relación parece responder al cumplimiento de un nuevo peaje comercial muy habitual en la época del cine del destape: la inclusión de desnudos y escenas sexuales.

Para empezar, ha de considerarse que, si bien Viota manifiesta su negativa a hacer cine "de autor" (Fernández Torres y G. Requena, 1979: 24), las escenas de sexo no dejan de suponer cierta marca autoral, una inclusión que puede verse como una concesión comercial pero también como un interés personal del cineasta, no en vano ya había escenas fuertemente eróticas en el proyecto anterior y el sexo, si bien en off, jugaba un papel no menor en Contactos, además de que la protagonista de Jaula de todos (1974) era presentada desnuda haciendo el amor, aunque fueran finalmente desechadas también había escenas eróticas en las primeras versiones de Cuerpo a cuerpo (1982), y sabemos que el erotismo fue objeto central de un proyecto de finales de los ochenta (Viota, 1985: 49). Pero, sobre todo, la dimensión sexual es tan problemática que no puede no verse como una apuesta del cineasta por introducir un elemento que no está directamente relacionado con la lucha obrera, y en busca, también en este caso, de romper con su articulación habitual.

Por ejemplo: aunque el disparador de la relación es la adrenalina producida por la persecución de Marcos y la salvadora aparición de Aurora, el acto tarda en llegar y en nada se asemeja a la liberación de las fuerzas animales desencadenadas por la tensión previa. Tampoco encontramos la huida de una relación conyugal adocenada o rutinaria, y no hay línea de diálogo alguna donde los personajes nos den alguna indicación que nos permita hacernos una idea de lo que allí está sucediendo: una cana al aire, el inicio de una historia de amor, la necesidad de un desahogo... No hay datos y ese es el reto: que dos personas hagan el amor sin que ello vaya en 
dirección alguna, sino que se mantenga en el campo de un presente donde dos personas han establecido una cercanía azarosa pero cierta. Las escenas de sexo entre Marcos y Aurora poseen algo de pasado, pero ni una gota de futuro: la cuestión en ellas no es qué sucederá sino el hecho mismo de su acontecer, el presente del mutuo descubrimiento y disfrute de los cuerpos. El sexo en Con uñas y dientes, tal como bien reflejó Iván Zulueta en el cartel de la película - donde los dos cuerpos se fusionan estilo Francis Bacon, aislados y rodeados por muros fabriles dominados por la ominosa figura del capitalista - es la celebración de ese presente arrancado a todo, lo cual puede no ser tan raro en el cine erótico, pero que aquí es al mismo tiempo presentado con una gravedad que lo aleja del erotismo festivo o la alegría de los cuerpos sexuados del cine del destape. G. Santamaría alabará la "historia de un amor que se nutre de la solidaridad cotidiana, que toma el sexo como fuente de reconocimiento" (G. Santamaría, 1979): al llegar en el primer día a casa de Aurora, Marcos contempla silencioso el espacio desde el sofá; en el tercer día, al volver tras la escena en el coche, se acerca a la mesa de ella y ojea sus libros y cuadernos de notas, pasando poco más tarde a descubrir "su cuerpo casi de la misma forma en que descubre sus libros y objetos personales" (Company, 1979: 61). Marcos la contempla en un sentido nuevo, de la casa a los objetos cercanos a una escena erótica resuelta en tres largos planos focalizados en el descubrimiento de los cuerpos (únicas palabras: "no tengas prisa"), es decir en el presente del encuentro erótico, que por sí mismo se opone y contrasta con la violencia que constituye todo su contexto. 


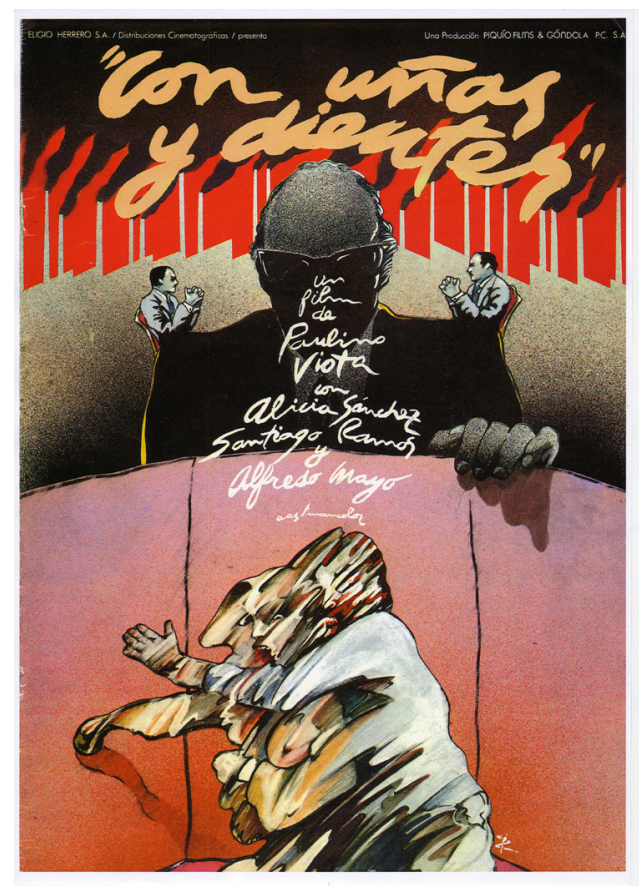

Figura 5

La mayor disonancia con el contexto genérico se encontrará en la escena de la violación, posiblemente uno de los momentos más violentos de todo el cine español, que no carece precisamente de ellos. El sexo consentido entre los dos camaradas es roto por la violencia de los matones de la patronal; la ternura, el cuidado, el respeto, opuestos como se dijo a la violencia ambiente, son finalmente invadidos por esta y replicados con la mayor brutalidad: no solo una violación, sino tres, de las que apenas se resume su tiempo real — solo la última de ellas es reducida a un plano-, de modo que cada sustitución de un violador por otro resulta más dura e inaceptable que la anterior ${ }^{12}$. La posibilidad que el destape y la desaparición de la censura ofrecían para mostrar escenas de sexo de forma moderadamente libre — recordemos la peculiar instauración del cine 
$\mathrm{S}^{13}$ - y casi siempre de modo alegre y despreocupado, es aquí reinvertido: el destape, el erotismo, ya no es - solo- la posibilidad de ver mujeres desnudas, sino la oportunidad de mostrar y denunciar el modo en que se ejerce la violencia sexual sobre ellas.

\section{LA TRANSICIÓN EN DISPUTA}

En el mismo número de Contracampo dedicado a Con uñas y dientes se encuentra una interesante crítica a 7 días de enero (1979), filme de Juan Antonio Bardem sobre los atentados de Atocha. Para su autor, Alberto Fernández Torres, 7 días de enero trata a las masas como comparsas, no ya no protagonistas de la historia sino ni siquiera un elemento activo o incluso presente en la misma, y no mostraría apenas interés por el lugar que los atentados de la extrema derecha jugaban en la Transición como elemento determinante en la neutralización de la lucha obrera y la moderación de sus representantes principales. Para el filme de Bardem la Transición sería un proceso duro, pero finalmente triunfal, una visión muy distinta y de hecho enfrentada a la de los autores de Contracampo, más próximos a la de un cineasta, Paulino Viota, al que no solo les unía el pensamiento político sino en varios casos también la amistad ${ }^{14}$.

Así como Viota y Vega consideran las posibles contradicciones dentro del movimiento obrero, hacen lo propio con las de la patronal. Marcos sabe de la estafa de Rodolfo por un miembro de la propia directiva de la fábrica, perteneciente a un grupo enfrentado al director. Marcos es, desde este punto de vista, un peón en una estrategia que solo tiene el objetivo de forzar un cambio de poder en la dirección de la empresa. Con uñas y dientes, fiel defensora de la necesidad de hablar alto y claro, entra aquí en el ámbito de lo no tan manifiesto: si lo evidente es el discurso sobre la lucha de clases, la necesidad de mantener la unidad entre los obreros y evitar los liderazgos excesivos, la trama interior a la empresa y el modo en que acabará afectando a la situación de los obreros - descubierta la estafa la empresa, en crisis, pide a los trabajadores que abandonen la

\footnotetext{
${ }^{13}$ Establecida en noviembre de 1977 y que define algo similar al erotismo softcore (Freixas y Bassa, 2000: 148).

${ }^{14}$ De hecho, Francisco Llinás, fundador y director de Contracampo, participó en la realización de Con uñas y dientes en calidad de adjunto de producción. Javier Vega, coguionista del filme y familiar de Viota, era también colaborador habitual de la publicación.
} 
huelga a riesgo de que se declare el cierre- pone en escena algo más subterráneo: un diagnóstico sobre la transición en curso, "una metáfora sobre la reforma" (Samaniego, 1979).

La lucha de clases es representada en un contexto entendido como el de un paso de la dictadura a la democracia en el que se intentaría neutralizar a la izquierda y adaptar el aparato estatal franquista a la forma de un régimen democrático sin cambios excesivamente traumáticos. Así, el filme concluirá con una escena final en la que se muestra que el juego de poder interno de la empresa lleva a que la lucha obrera deba ser abandonada en aras del beneficio común que, debido a que las relaciones de poder no han cambiado, es no otro que el beneficio de aquella ${ }^{15}$. Así, como nuevamente destacará Pérez Perucha:

[exponiendo la] circunstancia mediante la que se produce el relevo de una patronal — gestora del capital - corrupta y obsoleta por una nueva patronal, representante de un nuevo bloque económico, más flexible y acorde con las circunstancias económicas [...] se pone de relieve, asimismo, cómo en la reforma suarecista confluyeron tanto la lucha de masas como las contradicciones internas del capitalismo español, contradicciones agudizadas por esa lucha (Pérez Perucha, 1979a: 15).

El plano manifiesto, pues, la huelga, existe como representación de la lucha de clases, pero asimismo como metáfora de un proceso transparente para muchos en sus intenciones. Con uñas y dientes se convierte así no tanto en la primera película sobre la lucha de clases de la Transición cuanto en la primera en hacer este diagnóstico sobre su naturaleza y desarrollo.

Esta oposición señalada en Contracampo no es anecdótica. El trabajo de los hermanos Pérez Merinero y el colectivo Marta Hernández, y del NFC en general, su lectura de la historia del cine español y más concretamente del periodo que arranca con las Conversaciones de Salamanca de 1955 y sobre todo la Ley de Cinematografía del 14 de agosto de 1964, insistía en explicar cómo los años 60 y 70 estaban fundamentalmente marcados por la entrada en escena de una burguesía que ya no era la lumpen-burguesía alimentada por la corrupción propia

\footnotetext{
${ }^{15}$ Para un excelente análisis de este plano-secuencia final, que ejemplifica cómo, pese a que el planteamiento global de las relaciones forma-ideología fuera distinto al de Contactos, no por ello dejó Viota de pensar la forma cinematográfica como productora de sentido, ver Zumalde (2015: 238-239).
} 
de los años de la autarquía sino que avanzaba al paso de la lenta entrada en España de elementos de la economía capitalista, que inevitablemente generaban a su paso determinadas contradicciones con el sistema político dictatorial que dirigía España en aquel periodo, que trataba de impostar una cierta liberalización y apertura donde el cine podía jugar buen papel ${ }^{16}$. La crítica progresista llamaría la atención sobre la modernización del cine español -incrementando su valor de cambio ante la clase intelectual a la que estaba destinado, por ejemplo, el Nuevo Cine Español (NCE)sin considerar que su oposición al franquismo iba de la mano del apoyo al capitalismo, y que en ambos casos las clases trabajadoras quedaban desatendidas, como bien podía verse por su ausencia en el cine español, que fundamentalmente se dedicaba al retrato de universos e intereses de las clases burguesa y media, ya fuera a través de las películas del NCE, de la Escuela de Barcelona o la comedia desarrollista ${ }^{17}$. Con uñas y dientes, que retrata la Transición como un recambio de élites donde la burguesía capitalista sustituye a la lumpen-burguesía franquista, y metafóricamente traza el mismo juicio sobre el campo político, no podía por menos de ser defendida frente a otra película donde el mismo proceso era a su entender reducido a la mera derrota de las fuerzas fascistas y el triunfo de las democráticas. Para los autores de Contracampo tal balance carecía de detalle, complejidad y verdad.

Contracampo, fundada por un miembro de Marta Hernández, será el principal órgano de expresión de muchos miembros del NFC en los tramos finales de la Transición, y por ello sus textos muestran el balance que la izquierda radical hacía ya de la misma. En la valoración del filme de Bardem juega no en vano un papel no menor la presencia del PCE. Así, Fernández Torres denunciaba cómo la película, al centrar su narración en los fascistas, se atraía el apoyo fácil, emocional y acrítico de un público inequívocamente de izquierdas, de modo que más que una reflexión o un análisis, lo que se acababa planteando era "una adhesión o un rechazo moral. O se está con los fascistas, o se está contra ellos — con las masas..., con el PCE, en última instancia-—" (Fernández Torres, 1979). Y decir PCE en 1979 no era para muchos lo mismo que decirlo en 1970. A partir sobre

\footnotetext{
${ }^{16}$ Un excelente resumen del análisis que los autores del NFC realizaban del periodo franquista puede leerse en Pérez Merinero (1976: 9-46).

${ }^{17}$ Sobre otros cines y su incidencia social, véase Hernández (1976: 59-73).
} 
todo de 1968 el PCE ya no es el partido hegemónico del antifranquismo en la misma medida en que lo era hasta entonces, hasta el punto de que es justo considerar que la distancia entre la crítica progresista y el NFC reflejaba también, y quizá sobre todo, la existente entre un antifranquismo vinculado al PCE y otro a partidos más a su izquierda, como la Liga Comunista (LC) o sobre todo el Movimiento Comunista de España (MCE), al que pertenecerá parte importante del $\mathrm{NFC}^{18}$.

La Transición no hará más que agrandar esta distancia. Para muchos militantes de izquierda la posición del PCE fomenta la desmovilización social al tiempo que bendice y disfraza un proceso contrario a su credo político. En su crítica, Fernández Torres, tras denunciar la adhesión emocional antecitada, afirma lo siguiente:

Esta adhesión emocional del espectador $-y$, por tanto, acrítica, casi inconsciente-, subrayada en un final catárquico con las impresionantes imágenes del entierro de los compañeros laboralistas asesinados en la calle de Atocha, acompañadas por un fondo musical épico y grandilocuente, sirve indirectamente para salpicar, de forma casi imperceptible, el film de menciones y detalles iconográficos relativos al PCE, y en última instancia para cubrir un discurso político que subraya que los únicos enemigos de la democracia eran —son-los fascistas, que el rey está contra ellos - la aparición del helicóptero real durante el sepelio marca el comienzo del retroceso y catástrofe de los fascistas-, que no todos los policías son iguales, que la preocupación máxima de la izquierda debe ser la de "no provocar, ni caer en provocaciones" —estas frases se repiten insistentemente a lo largo de los diálogos - y, en definitiva a dar un juicio, que no análisis, del proceso de reforma como un proceso positivo que, efectivamente, trae la democracia a España. Un triunfo, pues (Fernández Torres, 1979).

Así, para el NFC podría hablarse de un cine de la "ruptura

\footnotetext{
${ }_{18}$ Para más señas, el nuevo logotipo del MCE al convertirse en MC a secas en 1976, es obra de José Luis Téllez, crítico y maquetador de Contracampo, de la cual militaron también en el partido su director Francisco Llinás, Pérez Perucha y Fernández Torres — sobre la política del MC y Marta Hernández, ver López Sangüesa (2019: 48) —. Manuel Vidal Estévez — que no militó en el MC - afirmará que "la Transición española desplegó una pugna entre los llamados reformistas y los llamados rupturistas" (Aranzubia, 2020: 107). En palabras de Javier Maqua, "todos éramos partidarios de la ruptura, contrarios a la política revisionista del PCE y estábamos por enfrentarnos a ciertos tópicos de la cultura de izquierdas, dominada durante todo el franquismo por el PCE" (Aranzubia, 2016: 255).
} 
pactada"19, al que se opondría Con uñas y dientes a través de la elección de sus protagonistas - la clase obrera-, su acción — la huelga- y su discurso - solo la lucha de las clases trabajadoras les traerá la libertad- . Pero en 1979, año del tardío estreno madrileño del filme, el balance empieza a ser claramente negativo, con los partidos de la izquierda alternativa desbancados en las elecciones por el PSOE y — cada vez menos - el PCE, y España convertida en una nueva democracia capitalista europea. La lumpenburguesía cinematográfica seguía activa si bien de forma marginal, y tardaría poco en desaparecer, con la ley Miró (1983) como último aldabonazo. Más tarde, los críticos del NFC se verán progresivamente relegados al mundo universitario, dominados los medios generalistas por los críticos progresistas, bendecidos por la oficialidad socialista. Resumido décadas después en palabras de Javier Maqua:

La derrota de los partidarios de la Ruptura frente a los de la Reforma fue total en las elecciones del 77 y se culminó con la entrada en la OTAN, ya con el PSOE en el Gobierno. A partir de entonces, a los derrotados, ni agua. En escala minúscula, el caso de la crítica y teoría del cine solo fue uno más. Los representantes de la crítica social-gacetillera supuestamente progresista, cuyas posiciones y discursos el Nuevo Frente Crítico había combatido, accedieron y rigieron importantes instituciones del Aparato Cinematográfico; el Nuevo Frente Crítico quedó huérfano y fue, poco a poco, amordazado (Aranzubia, 2016: 259).

El balance es pues sumamente negativo, y nuevamente la entrevista a Viota es buen ejemplo de ello. Si las páginas finales de El aparato cinematográfico español, duramente condenadas por los Pérez Merinero (Pérez Merinero, 1976: 69-71), afirmaban la necesidad del desarrollo de la burguesía cinematográfica para consolidar el aparato y que los beneficios de una industria saneada y racionalmente organizada pudieran ser lo suficientemente amplios como para poder emplearse en productos menos

\footnotetext{
${ }^{19}$ Instalada la oposición tras la muerte de Franco en el dilema sobre si plantear una reforma pactada o una ruptura con el sistema franquista, el PCE introdujo el término ruptura pactada, acuñado originalmente según Gregorio Morán por el secretario general del Partido Socialista Popular (PSP) Raúl Morodo, según el cual el término no sería "más que un modo diplomático para girar de ruptura a reforma sin necesidad de rasgarse las vestiduras y conmover los ánimos militantes" (Morán, 1986: 516). Algunos autores como Jorge Nieto han extendido la dicotomía entre reforma y ruptura al cine, situando Con uñas y dientes en el segundo grupo: "cine popular, incluso genérico y panfletario, digerible con facilidad, pero con una carga política demoledora" (Nieto Ferrando, 2012: 46).
} 
seguros económicamente, más heterodoxos y arriesgados (Hernández, 1976: 259), en cierto modo el final de la década de los 70 empezaba a dar otra impresión: que con la lumpen-burguesía y la corrupción autárquica moría paradójicamente la posibilidad de esas películas, ya que si su distribución seguía siendo tan difícil como siempre, dominada la exhibición por la rendición sin condiciones a las majors estadounidenses, la producción devenía cada vez más imposible, dominada la protección por la atención a los rendimientos económicos ${ }^{20}$. Viota concluye la entrevista afirmando "yo fui cineasta" (Fernández Torres y G. Requena, 1979: 25) y aunque aún logrará hacer, autoproducido y con extremas dificultades, un tercer largometraje, su carrera no podrá ya avanzar más. Si Con uñas y dientes es un balance político de la Transición vista desde su inicio, Cuerpo a cuerpo, realizada en 1982, será uno sociológico: los jóvenes opositores del antifranquismo son los viejos de la nueva democracia, condenados al fracaso intentando tomar el pulso a las nuevas generaciones o conquistando algún pequeño reducto que les permita sobrevivir, con cierta dignidad, al mucho más cierto naufragio.

\section{REFERENCIAS BIBLIOGRÁFICAS}

ANTOLÍN, M. (1979). “Con uñas y dientes”. Cinema 2002 52, 46-49. ARANZUBÍA, A. (2016). "Marta Hernández y el análisis textual. Entrevista con Javier Maqua". En Los mecanismos comunicativos del cine de todos los días, M. Hernández y J. Maqua, 252-260. Santander: Shangrila (2020). "Bulevar de los recuerdos. Una conversación con Manuel Vidal Estévez". Materiales por derribo 5, 3-196.

BAYÓN, M. (1979). "El libre juego mata al cine español”. Diario16, 15. BORDWELL, D. (1996). La narración en el cine de ficción. Barcelona: Paidós.

BREMOND, C. (1972). "La lógica de los posibles narrativos". En Análisis estructural del relato, Roland Barthes et alii, 87-109. Buenos Aires: Editorial Tiempo Contemporáneo.

\footnotetext{
${ }^{20}$ Véanse las declaraciones al respecto de Viota en Samaniego (1979): "He pretendido hacer una película popular".
} 
COMOLLI, J.-L. y NARBONI, J. (2008 [1969]). “Cine / Ideología / Crítica". Cahiers du Cinéma España 11, 76-82.

COMPANY, J. M. (1979). "Paulino Viota y el desafío de Con uñas y dientes". Dirigido por ... 64, 58-61.

FERNÁNDEZ TORRES, A. (1979). "Siete días de enero". Contracampo 2, 66.

FERNÁNDEZ TORRES, A. y G. REQUENA, J. (1979). "El presente como historia. Entrevista con Paulino Viota". Contracampo 2, 1625.

FREIXAS, R. y BASSA, J. (2000). El sexo en el cine y el cine de sexo. Barcelona: Paidós.

GARCÍA LÓPEZ, R. (ed.) (2015). Paulino Viota. El orden del laberinto. Santander: Shangrila.

(2017). Paulino Viota: vanguardia y retaguardia del cine español. Madrid: Universidad Carlos III, https://es.scribd.com/ document/343390564/Ruben-Garcia-Lopez-PAULINO-VIOTAVanguardia-y-retaguardia-del-cine-espan-ol [27/04/20].

G. SANTAMARÍA, J. (1979). "Con uñas y dientes: una película sin concesiones". El Día, s.p.

HERNÁNDEZ, M. (1976). El Aparato Cinematográfico Español. Madrid: Akal.

HERNÁNDEZ, M. y MAQUA, J. (2016). Los mecanismos comunicativos del cine de todos los días. Santander: Shangrila.

LATORRE, J. M. (1979). “Con uñas y dientes". Dirigido por ... 64, 64-65.

LÓPEZ SANGÜESA, J. L. (2019). “Abrir las puertas del mar”. En su obra, Crisis y agonía del cine español (1939-2018), 5-93. Madrid: Cisma.

MORÁN, G. (1986). Miseria y grandeza del Partido Comunista de España 1939-1985. Barcelona: Planeta.

NARBONI, J.; PIERRE, S. y RIVETTE, J. (1969). “Montaje”. Cahiers $d u$ Cinéma 210, 17-34.

NIETO FERRANDO, J. (2012). Cine en papel. Cultura y critica cinematográfica en España (1962-1982). Valencia: Ediciones de la Filmoteca.

PENA, J. (1997). “Contactos”. En Antología crítica del cine español 19061995, J. Pérez Perucha (ed.), 677-679. Madrid: Cátedra.

PÉREZ MERINERO, C. y D. (1973). Cine español: algunos materiales 
por derribo. Madrid: Edicusa.

(1976). Cine español: una reinterpretación. Barcelona: Anagrama.

PÉREZ PERUCHA, J. (1979a). "Crónica de un reto". Contracampo 2, 14-15.

(1979b). "Crónica de un reto, 2". Contracampo 4, 10-18.

RODRÍGUEZ LÓPEZ, E. (2015). Por qué fracasó la democracia en España. La transición y el régimen del '78. Madrid: Traficantes de Sueños.

SAMANIEGO, F. (1979). "He pretendido hacer una película popular". El País, https://elpais.com/diario/1979/05/29/ cultura/296776811_850215.html [27/04/20].

VIOTA, P. (1985). "Entrevista". Cuadernos de Cine 7, 33-61. (1997). "Historiarelpresente".EnLaimagennegada.Representaciones de la clase trabajadora en el cine, José Enrique Monterde (ed.), 271-274. Valencia: Filmoteca Generalitat Valenciana.

ZUMALDE, I. (2015). “Crónica de un desencanto". En Paulino Viota. El orden del laberinto, R. García López (ed.), 222-241). Santander: Shangrila.

Recibido el 24 de marzo de 2019.

Aceptado el 5 de mayo de 2020. 